\section{A PROVISORIEDADE DO CONHECIMENTO CIENTÍFICO: UMA REFLEXÃO SOBRE A FILOSOFIA DA CIÊNCIA DE KARL POPPER}

\author{
Fátima Siqueira Caropreso*
}

Como comenta Alan Chalmers (1999, p.17), nos tempos modernos é dada muita importância à ciência. Parece haver uma crença amplamente aceita de que há algo de especial a respeito da ciência e de seus métodos. Por isso, freqüentemente se atribui o termo "científico" a certos dados com o objetivo de assegurar sua confiabilidade.

Tal alta estima pela ciência está presente não apenas no mundo escolar e acadêmico, mas também na vida cotidiana e na mídia popular. Anúncios freqüentemente asseguram que a eficácia dos produtos foi cientificamente comprovada ou, de alguma outra forma, associam seus produtos à idéia de ciência.

Mas o que é a ciência afinal? Há de fato alguma garantia de verdade no conhecimento obtido “cientificamente”? A primeira dessas questões, como vem mostrando a filosofia da ciência, não pode ser definitivamente respondida, uma vez que há não apenas uma, mas inúmeras concepções de ciência. Os requisitos para se considerar as diversas áreas de conhecimento científico não podem ser os mesmos para todas elas. Quanto à segunda questão, a resposta é negativa. $\mathrm{O}$ conhecimento científico sem dúvida é um conhecimento muito superior àquele do senso comum; é um conhecimento que nos fornece um grau de segurança maior, mas não é e nunca virá a ser um conhecimento absolutamente verdadeiro afinal, porque verdades absolutas não são possíveis. A filosofia da ciência de Karl Popper (1902-1994) pode ajudar a nos esclarecer o por quê.

\section{A concepção indutivista de ciência}

Popper formula sua concepção sobre a natureza do conhecimento científico em oposição à concepção indutivista de ciência. De acordo com esta última, o conhecimento científico consistiria em um conjunto de proposições gerais e “verdadeiras” obtidas a partir da generalização de proposições sobre

* Doutora em Filosofia pela Universidade Federal de São Carlos. Professora do curso de Psicologia do Centro Universitário de Araraquara - Uniara. E-mail: fatimacaropreso@uol.com.br. observações singulares. A hipótese de que a partir de proposições de observações singulares é possível, por generalização, obter leis gerais, apoia-se no seguinte princípio: "Se um grande número de As foi observado sob uma ampla variedade de condições e se todos esses As possuem a propriedade B, então, todos os As possuem a propriedade B.” (CHALMERS, 1999).

Como as observações singulares seriam inteiramente objetivas, as proposições gerais que constituem o conhecimento científico também o seriam. O conhecimento verdadeiro seria o conhecimento puro, ou seja, onde nenhum fator subjetivo interviesse. Portanto, a ciência começaria com a observação, e as hipóteses seriam decorrentes destas observações.

Então, a concepção indutivista pressupõe, em primeiro lugar, que é possível uma observação inteiramente objetiva. Em segundo lugar, ela pressupõe que, na ciência, a experiência sempre precede a teoria e, em terceiro, pressupõe que é possível alcançar um conhecimento "verdadeiro". A objetividade e a verdade das proposições sobre observações singulares seriam transmitidas para a lei geral. A atividade científica seria constituída por dois estágios: um indutivo, do qual resultariam as leis gerais; e um dedutivo, no qual seriam feitas explicações e previsões. À medida que a capacidade de observação se aperfeiçoasse, surgiriam teorias e leis de maior generalidade e alcance; assim, o crescimento da ciência seria contínuo e progressivo.

No entanto, o princípio de indução, sob o qual tal concepção de ciência se baseia, não pode ser fundamentado nem se recorrendo à lógica nem à experiência. Ele não pode ser fundamentado com base na lógica, porque uma proposição geral não pode ser deduzida validamente de proposições singulares, uma vez que é possível que as últimas sejam verdadeiras e a primeira falsa, sem que o argumento seja contraditório.

Para justificar o princípio da indução a partir da experiência, seria preciso recorrer a uma explicação indutiva, ou seja, buscar proposições singulares que corroborassem tal princípio e, a partir delas, generalizar que "o princípio de indução é sempre bem sucedido”. Dessa forma, a questão seria explicada a partir do fato a ser explicado, isto é, ela não seria explicada.

Há também outros problemas levantados pelo princípio da indução, como, por exemplo, a dificuldade de se estabelecer o que exatamente seria "um grande número de observações” e o que exatamente seria "uma ampla variedade de condições".

\section{A aprendizagem é como um holofote e não como um balde}

A filosofia de Popper se opõe a essa concepção indutivista da ciência e à teoria do conhecimento a ela subjacente.

No texto "O balde e o holofote: duas teorias do conhecimento" (1975), antes de propor o seu esquema lógico da ciência, ele expõe a teoria do 
conhecimento que fundamenta sua teoria e a contrapõe ao que ele chama de “teoria do balde mental”. De acordo com a teoria do conhecimento implícita na teoria indutivista - o empirismo ingênuo ${ }^{1}$ - a mente seria como um recipiente vazio - um balde - onde as diversas impressões sensoriais seriam depositadas, diz Popper ${ }^{2}$. Conseqüentemente, a aprendizagem consistiria num acúmulo de informações sensoriais e toda idéia seria precedida por uma experiência.

Em contraposição a isto, Popper propõe que a aprendizagem consista num processo de modificação das “disposições inatas” do organismo para reagir. Essas disposições, chamadas também de "expectativas”, seriam as formas possíveis de reação a estímulos externos que o indivíduo possui.

Cada organismo possuiria um conjunto inato de disposições para reagir, o qual constituiria o “estado interior do organismo”. O indivíduo só “aprenderia com a experiência” se suas disposições inatas para reagir mudassem no decorrer do tempo e se tivéssemos razão para supor que essas mudanças não dependem meramente de alterações inatas no estado do organismo, mas também de alterações no ambiente externo. Isso seria uma condição necessária, embora não suficiente, para que haja aprendizagem. Sendo assim, a aprendizagem seria uma mudança nas disposições de um organismo para reagir, impulsionada por estímulos externos, e não uma acumulação de impressões sensoriais.

Como se daria essa modificação das expectativas, das disposições para reagir? Ela seria decorrente da frustração.

Nossas expectativas, quando frustradas, se reorganizariam para tentar corrigir o problema ou para evitar futuras decepções, e estas correções constituiriam, para Popper, o processo de aprendizagem. Portanto, a aprendizagem consistiria na eliminação de expectativas falsas. Segundo ele, essas expectativas não seriam necessariamente estados conscientes, pois, muitas vezes, elas se tornam conscientes apenas quando frustradas. Por exemplo, se estamos andando na rua e, de repente, tropeçamos, só então nos damos conta de que possuíamos a expectativa de que o caminho fosse plano.

1. Ele refere-se explicitamente a Bacon.

2. Ele critica também concepção de Kant sobre o conhecimento. Segundo ele, Kant nega que as percepções possam ser puras e defende que nossa experiência é o resultado de um processo de assimilação e transformação, isto é, ela seria "o produto combinado de percepções dos sentidos e certos ingredientes acrescentados pela nossa mente”. Popper diz que, de acordo com essa concepção, as percepções seriam "a matéria prima que flui de fora para dentro do balde, onde ela experimentaria um processamento automático - algo parecido com a digestão ou com uma classificação sistemática”. Ele recusa tal concepção, embora admita que ela se aproxima mais da sua do que a do empirismo. Para Bacon, o conhecimento é como um vinho, exprimido da nossa experiência, mas que já nos alcança pronto. Para Kant, o conhecimento é um vinho fermentado na nossa cabeça.
Popper, então, recusa a "teoria do balde mental”, que fundamentaria a concepção indutivista da ciência, e a substitui pela "teoria do holofote mental”, sobre a qual ele apoia sua concepção de ciência. A mente seria algo que ilumina o mundo externo e não um balde que receberia passivamente as informações dele provenientes.

A observação seria a confirmação de expectativas formuladas na forma de questões. Então, toda observação pressuporia uma hipótese, ou seja, a teoria sempre a precederia. Todas as pessoas possuiriam um "horizonte de expectativas”, e as observações, assim como nossas demais experiências, obteriam significado apenas quando vistas sobre o pano de fundo desse horizonte. Certas observações poderiam destruir parte deste pano de fundo e, quando isto ocorresse, surgiria um "problema" - um evento que não se encaixaria no nosso horizonte de expectativas -, o qual levaria a uma tentativa de reconstruir as partes dilaceradas, ou seja, de alcançar um novo horizonte de expectativas, no qual as partes intactas do horizonte anterior permaneceriam, e as partes destruídas estariam reconstruídas e integradas às demais. Quando essa tarefa fosse cumprida, teria sido alcançada uma explicação para o problema. Portanto, explicar seria reconstruir expectativas frustradas.

Então, ao contrário dos indutivistas, Popper propõe que a observação seja um processo no qual o sujeito desempenha um papel ativo. Toda observação é precedida por um interesse em particular, uma indagação, isto é, a observação é sempre precedida por uma hipótese, por algo, em última instância, teórico. Assim, não "temos” uma observação, mas “fazemos" uma observação, e a objetividade total das observações - a qual constituiria o fundamento da ciência para os indutivistas - é algo irrealizável para Popper. Ele recusa a possibilidade de conhecimento puro e, portanto, de observação inteiramente objetiva. Não é a experiência, mas sim nosso horizonte de expectativas que estaria na base do conhecimento.

Embora as observações sejam secundárias em relação às hipóteses, elas exerceriam um papel importante como “testes” que as hipóteses devem experimentar. Quando uma hipótese não passasse no teste, partir-se-ia para a busca de uma nova hipótese, para a reconstrução de parte do nosso horizonte de expectativas. O processo de conhecimento seria, assim, um processo de desconstrução e reconstrução do horizonte de expectativas.

Segundo Popper, a ciência teria surgido como uma continuação direta do trabalho pré-científico de consertar horizontes de expectativas, e o que teria caracterizado o seu início seria o surgimento de uma nova atitude para com os mitos tradicionais que tentavam explicar o universo. A ciência teria surgido quando estes mitos, ao invés de serem aceitos passivamente e transmitidos dogmaticamente de geração a geração, passaram a ser encarados criticamente e contrapostos a observações. 


\section{A ciência segundo Popper}

As teorias científicas seriam conjecturas especulativas criadas livremente pelo intelecto humano no sentido de superar problemas encontrados por teorias anteriores e dar uma explicação adequada do comportamento de algum aspecto do mundo. A ciência, portanto, basearia-se apenas na dedução. Popper (1975) recusa a parte indutiva da ciência, propondo que as teorias sejam criadas livremente pelo intelecto.

A tarefa da ciência, para Popper, seria, em parte, teórica - explicar - e, em parte, prática - prever e aplicar tecnicamente. Ele explica essas três atividades a partir do seguinte esquema lógico:

1) Leis universais

2) Condições iniciais

3) "Explanandum"

As leis universais e as condições iniciais constituiriam o "explanans" (aquilo que explica). Prever seria, a partir do "explanans", deduzir o "explanandum" (aquilo que está sendo explicado), ou seja, a partir de certas leis universais e condições iniciais, deduzir ou inferir uma conclusão.

A aplicação técnica consistiria na busca de certas condições iniciais, a partir de leis gerais dadas e de um "explanandum", isto é, consistiria em encontrar certas condições iniciais que pudessem ser realizadas tecnicamente e que, quando vistas em relação a certas leis gerais, tornassem o "explanandum" uma conseqüência lógica. Por exemplo, se eu tenho que construir uma ponte com as características X, é preciso, dadas certas leis físicas, encontrar condições específicas que tornem possível a construção de uma ponte com as características X.

A explicação consistiria no processo oposto ao da previsão, ou seja, em encontrar um "explanans” a partir de um "explanandum”. Desse modo, as três tarefas da ciência seriam inversões do esquema básico da explicação científica. Na explicação, teríamos 3 e precisaríamos encontrar 1 e 2; na previsão, teríamos 1 e 2 e precisaríamos encontrar 3 e, na aplicação técnica, teríamos 1 e 3 e precisaríamos encontrar 2.

Mas em que se fundamentariam as explicações científicas? Em algo que apóie o “explanans” independentemente do “explanandum”, argumenta Popper. Tanto as condições iniciais quanto a lei geral teriam que apresentar a possibilidade de serem testáveis independentemente do "explanans". Portanto, toda lei geral deve poder ser testada. Por exemplo:
Se um rato come pelo menos 8 grãos de veneno para ratos, ele morre dentro de 5 minutos. 5 minutos.

Este rato comeu pelo menos 18 grãos de veneno para ratos há mais de

$$
\text { Este rato morreu recentemente. }
$$

Nesta explicação, seria possível apoiar a condição inicial constatando que, de fato, havia no estômago do rato a quantidade de veneno suficiente para provocar a morte, ou seja, submetendo-a a testes empíricos.

Para apoiar a lei geral também seria necessário submetê-la a testes e, embora estes não sejam capazes de garantir sua verdade, eles poderiam falsificá-la. Dessa forma, uma explicação satisfatória seria aquela cujas premissas são testáveis empiricamente. $O$ fato de que uma explicação satisfatória é aquela que pode ser testada independentemente do "explanandum” conduz à exigência metodológica de que as teorias sejam falsificáveis ${ }^{3}$. Então, uma teoria científica deve poder ser falsificada e é a possibilidade de ser falsificada, a sua submissão a testes continuamente e a não falsificação que permitiriam que uma teoria fosse chamada de científica. A falsificabilidade seria o critério de demarcação da ciência.

O processo de teste também pode ser analisado a partir do esquema acima. Testar consistiria em derivar do "explanans" uma predição e comparála com uma situação observável. Se a predição não concordasse com os dados empíricos, o "explanans" seria falso. Nesse caso, ou a lei universal ou as condições iniciais, ou ambas, poderiam ser falsas.

A falsificação da predição mostra que o "explanans" é falso, mas a confirmação da predição não quer dizer que ele seja verdadeiro, uma vez que é possível que uma predição verdadeira seja extraída de um "explanans" falso, ou seja, que uma conclusão verdadeira seja deduzida validamente de premissas falsas. Portanto, embora seja impossível verificar uma teoria ou assegurar sua veracidade, é possível falsificá-la.

Popper aproveita essa particularidade lógica. Se a conclusão de um argumento é falsa e o argumento é válido, ao menos uma das premissas é falsa. Já um argumento válido pode possuir conclusão verdadeira e premissas falsas. Com isso, Popper mostra a impossibilidade de que o conhecimento científico seja um conhecimento "verdadeiro" e propõe que deve ser considerado científico o conhecimento falsificável, aquele que tenha sido submetido a testes freqüentemente e não tenha sido refutado por eles.

3. Não apenas ser testável, pois uma afirmação contraditória pode ser testada, embora não possa ser falsificada. Por exemplo, a afirmação: “Chove ou não chove às segundas-feiras” pode ser testada, mas nunca falsificada. 
Quanto mais falsificável uma teoria, melhor ela seria. A falsificabilidade da teoria aumentaria com seu grau de “universalidade” e de “precisão”. Quanto mais universal uma teoria, maior o número de eventos a respeito dos quais ela pode fazer predições e, então, maior são as possibilidades de testá-la. Quanto mais precisa for uma afirmação, mais facilmente ela pode ser refutada.

A falsificação de uma teoria levaria à busca de uma nova teoria que contivesse as partes não falsificadas da anterior, que explicasse as partes falsificadas desta e que, talvez, fosse aplicável a novos fenômenos. Embora não seja possível afirmar que uma teoria é verdadeira, é possível afirmar que ela é “a melhor disponível”, que ela é superior as suas predecessoras no sentido de que ela é capaz de superar os testes que falsificaram as precedentes. A tarefa do cientista, dessa forma, consistiria em submeter suas hipóteses sempre a novos testes e formular novas hipóteses quando as anteriores fossem falsificadas, as quais seriam submetidas a outros testes e assim por diante. Portanto, o progresso da ciência consistiria na eliminação de erros.

Popper nos mostra que a aspiração de verdade do conhecimento científico é irrealizável. Uma vez que as teorias científicas contêm leis gerais e que o mundo é um sem-fim de possibilidades, nunca é possível garantir a verdade de uma proposição geral. Desfeita a ilusão de que a ciência pode aspirar a um conhecimento verdadeiro, Popper propõe que se considere científico o conhecimento falsificável, testado continuamente e que resiste aos testes, ou seja, falsificável, mas não (ainda) falsificado. O conhecimento científico seria, portanto, um conhecimento sempre em aberto. Em contínuo, mas nunca definitivo, progresso.

\section{Referências:}

CHALMERS, A.F. O que é ciência afinal? São Paulo: Brasiliense, 1999.

POPPER, K.R. A miséria do historicismo. São Paulo: Cultrix, 1961.

. Autobiografia intelectual. São Paulo: Cultrix, 1977.

O balde e o holofote: duas teorias do conhecimento. In: POPPER, K.R. O conhecimento objetivo. São Paulo: Itatiaia Edusp, 1975, p.313-332.

\section{Resumo:}

A concepção de ciência de Karl Popper nos mostra que esta, embora indubitavelmente nos forneça um conhecimento muito mais seguro do que aquele do senso comum, jamais poderá alcançar um conhecimento verdadeiro, definitivo. A aspiração de verdade da ciência consiste em uma impossibilidade lógica e empírica, portanto, o conhecimento científico deve ser conhecimento falsificável e não falsificado, que se desenvolve a partir de um processo de eliminação de erros. O objetivo deste artigo é apresentar a concepção de ciência de Popper, o que parece se justificar por nos lembrar da provisoriedade das teorias científicas, em uma época em que há uma confiança muitas vezes ingênua nos dados científicos, principalmente nos meios não acadêmicos.

\section{Palavras-chave:}

Filosofia da Ciência, Popper, Conhecimento, Indução, Falsificação. 